\title{
Intense Tropical Thunderstorms Detected by the Special Sensor Microwave Imager/Sounder
}

\author{
Gang Hong and Georg Heygster, Member, IEEE
}

\begin{abstract}
The 150-GHz microwave window channel and the three water vapor channels, $183.3 \pm 7,183.3 \pm 3$, and $183.3 \pm$ 1 GHz of the Defense Meteorological Satellite Program's (DMSP) Special Sensor Microwave Imager/Sounder (SSMIS) are used to detect intense thunderstorms over the tropics $\left(30^{\circ} \mathrm{S}-30^{\circ} \mathrm{N}\right)$. This application utilizes the advantages of conical scanning and high surface horizontal resolution of the SSMIS compared to the same measurements made with cross-track scanning radiometers. The criteria to detect intense tropical thunderstorms are derived by the combination of the brightness temperature differences between the three water vapor channels and brightness temperatures at the four frequencies. One year of SSMIS data (December 2005November 2006) is surveyed for intense tropical thunderstorms. The most intense tropical thunderstorms are predominant over land and are mainly concentrated over Central and South America, tropical west Africa, and northern Australia. Over most regions these very intense tropical thunderstorms have a strong regional dependence and a pronounced seasonal migration.
\end{abstract}

Index Terms-Clouds, microwave measurements, microwave radiometry, remote sensing, Special Sensor Microwave Imager/ Sounder (SSMIS), thunderstorm.

\section{INTRODUCTION}

$\mathbf{T}$ ROPICAL thunderstorms consist of the most complex meteorological events. They play a major role in the global climate by transporting heat, moisture, and momentum from the lower to the upper troposphere [1]-[4]. They also influence the Earth's radiation budget by interacting with incoming shortwave and outgoing longwave radiations [5]-[7]. Additionally, intense thunderstorms can cause huge financial losses (e.g., [8]).

For over two decades, satellite observations providing high spatial and temporal resolution have been extensively used to detect tropical thunderstorms. These techniques include both active and passive measurements from sensors ranging from the visible over the infrared to the submillimeter and millimeter region of the electromagnetic spectrum (e.g., [9]-[18]).

Satellite-observed infrared and visible radiances are sensitive only to the top parts of clouds. The infrared brightness temperatures become saturated when the cloud's optical thickness is near 10 [19]. Because of this limitation, it is difficult to distinguish thunderstorms from their anvil cirrus shields that are tightly connected with thunderstorm systems (e.g., [18], [20], and [21]).

Manuscript received January 30, 2007; revised August 18, 2007.

G. Hong is with the Department of Atmospheric Sciences, Texas A\&M University, College Station, TX 77843 USA (e-mail: hong@ariel.met.tamu.edu).

G. Heygster is with the Institute of Environmental Physics, University of Bremen, D-28359 Bremen, Germany.

Digital Object Identifier 10.1109/TGRS.2008.915750
Because of the microwave frequencies' unique capability to penetrate clouds, they have been used to detect convective storms since the 1980s. Wilheit et al. [22] presented the aircraft measurements of microwave brightness temperatures at 19, 92, and $183 \mathrm{GHz}$, respectively, over tropical storms. Spencer et al. [9] examined the 37-GHz brightness temperatures over heavy thunderstorms observed over land by the Nimbus 7 Scanning Multichannel Microwave Radiometer (SMMR). Since the SMMR, several satellite microwave sensors have been carried on satellites to detect clouds and precipitation, including the Defense Meteorological Satellites Program (DMSP) Special Sensor Microwave/Imager (SSM/I), the Tropical Rainfall Measuring Mission (TRMM) Microwave Imager (TMI), and the Advanced Microwave Scanning Radiometer-Earth Observing System (AMSR-E). However, microwave radiances at frequencies less than $90 \mathrm{GHz}$ are influenced by the surface emissivity [13].

Radiances at high microwave frequencies covering 90-190 GHz have been observed by the DMSP Special Sensor Microwave Moisture (SSM/T2), the Advanced Microwave Sounding Unit-B (AMSU-B) aboard the National Oceanic and Atmospheric Administration (NOAA) satellite series, and the AMSU Humidity Sounder for Brazil (HSB) aboard the Aqua spacecraft. These high microwave frequencies are sensitive to scattering by the frozen hydrometeors in convective systems; therefore they have been employed extensively to study precipitation via detecting frozen hydrometeors (e.g., [4], [6], [16], [20], and [23]-[28]). Hong et al. [20] investigated the sensitivity of microwave brightness temperatures at the frequencies of $89-190 \mathrm{GHz}$ to surface emissivities and hydrometeors in a tropical deep convective cloud system.

The $89-\mathrm{GHz}$ window channel has an apparent dependence on surface emissivity. Under tropical conditions, the $150-\mathrm{GHz}$ window channel is nearly independent of surface emissivity, and the water vapor channels around $183.3 \mathrm{GHz}$ are completely independent. Based on the advantage of independence of surface emissivity for the water vapor channels around 183.3 GHz and their different sensitivities to frozen hydrometers in convective clouds, the $183.3 \pm 7-, 183.3 \pm 3-$, and $183.3 \pm 1-\mathrm{GHz}$ channels of the AMSU-B have been used to detect tropical deep convective clouds and convective overshooting [17] and convective strength [16].

All aforementioned microwave sensors with $183.3-\mathrm{GHz}$ channels use a cross-track scanning scheme so that any method to detect convective systems must consider the influence of variations of the satellite incident angle [17]. The first DMSP Special Sensor Microwave Imager/Sounder (SSMIS) was launched on October 18, 2003. The SSMIS is a passive microwave 
TABLE I

SPECIFICATIONS OF THE SSMIS CHANNELS USED IN THIS STUdY

\begin{tabular}{cccccc}
\hline $\begin{array}{c}\text { Center Frequencies } \\
(\mathrm{GHz})\end{array}$ & $\begin{array}{c}\text { Half Bandwidth } \\
(\mathrm{MHz})\end{array}$ & Polarization & $\begin{array}{c}\text { Instantaneous } \\
\text { Field of View }\end{array}$ & $\begin{array}{c}\text { Sample Spacing } \\
(\mathrm{km} \times \mathrm{km})\end{array}$ & $\begin{array}{c}\text { NED* at } 305 \mathrm{~K} \\
(\mathrm{~K})\end{array}$ \\
\hline $150.0 \pm 1.25$ & 1640 & $\mathrm{H}$ & $14 \times 13$ & $13 \times 16$ & 0.53 \\
$183.31 \pm 7.0$ & 1530 & $\mathrm{H}$ & $14 \times 13$ & $13 \times 16$ & 0.56 \\
$183.31 \pm 3.0$ & 1020 & $\mathrm{H}$ & $14 \times 13$ & $13 \times 16$ & 0.39 \\
$183.31 \pm 1.0$ & 510 & $\mathrm{H}$ & $14 \times 13$ & $13 \times 16$ & 0.38 \\
\hline
\end{tabular}

* NEDT is the noise equivalent temperature difference.

radiometer scanning conically at a $53.1^{\circ}$ Earth incidence angle. It includes 24 channels covering the wide frequency range of 19-183 GHz, thus combining the capabilities of the SSM/I, SSM/T-1, SSM/T-2, AMSU-A, and AMSU-B on a single platform and under a unified scanning system with a constant incidence angle. This avoids the errors caused by aligning scenes from separately cross-track and conically scanning instruments and by incidence angle variations. The channels above $90 \mathrm{GHz}$ of the SSMIS have a horizontal resolution of $14 \times 13 \mathrm{~km}$, which is higher than that of the SSM/T2 (resolution $48 \mathrm{~km}$ at nadir) and the AMSU-B $(20 \times 16 \mathrm{~km}$ at nadir and $64 \times 52 \mathrm{~km}$ at edge scanning [29]). Thus, the SSMIS is the first instrument to provide global observations at microwave frequencies between 150 and $190 \mathrm{GHz}$ at a high resolution and a constant incidence angle.

Zipser et al. [18] have used the observation technique to look for small percentages of extreme values to identify extreme thunderstorms from microwave observations at 37 and $85 \mathrm{GHz}$, respectively. Profiting from the advantages of conical scanning and high resolution of the SSMIS, this paper extends the technique of looking at extreme values to the high frequencies up to $190 \mathrm{GHz}$ to detect intense thunderstorms over the tropics $\left(30^{\circ} \mathrm{S}-30^{\circ} \mathrm{N}\right)$. The data and method are introduced in Section II. Section III presents the results, including the distributions and seasonal variations of intense tropical thunderstorms. Finally, the conclusions are presented in Section IV.

\section{DATA AND METHOD}

One year of the Level 1C data of the SSMIS from December 2005 to November 2006 obtained from the Precipitation Research Group at Colorado State University (http://mrain.atmos. colostate.edu/LEVEL1C/) [30] were used in this study. The dataset is based on the Sensor Data Record data produced by the Navy's Fleet Numerical Meteorology and Oceanography Center (FNMOC). The Level 1C calibration for the SSMIS was unchanged from the 1B data produced by the FNMOC. Only 11 channels of the total 24 channels most relevant to remotely sensing precipitation are contained in the Level 1C dataset. To avoid the influence of the surface, the channels at $150,183.1 \pm 7,183.1 \pm 3$, and $183.1 \pm 1 \mathrm{GHz}$, respectively, which are not sensitive to surface emissivity under tropical weather conditions with strong storms [20], are used to detect tropical thunderstorms. The channel specifications are shown in Table I [31].

The channels at 150 and $183.3 \mathrm{GHz}$, respectively, have been used to detect convective clouds [12], [16], [17], [21] or to screen out convective clouds before water vapor retrieval [32]-[35]. The methods for detecting convective clouds from
Hong et al. [17] and Ferraro et al. [16] are based on the brightness temperature differences between the channels at $183.3 \pm 1$ and $183.3 \pm 7 \mathrm{GHz}\left(\Delta T_{17}\right), 183.3 \pm 1$ and $183.3 \pm$ $3 \mathrm{GHz}\left(\Delta T_{13}\right)$, and $183.3 \pm 3$ and $183.3 \pm 7\left(\Delta T_{37}\right)$, respectively. Additionally, in the method of Hong et al. [17], a threshold value of $235 \mathrm{~K}$ for a $183.3 \pm 1-\mathrm{GHz}$ channel has been used to identify cold clouds associated with precipitation.

Cecil et al. [36] and Zipser et al. [18] identified intense thunderstorms using low brightness temperatures at 37 and $85 \mathrm{GHz}$, respectively. They documented that extremely intense storms are associated with lower brightness temperatures, caused by the scattering by the larger cloud ice particles $(>0.1 \mathrm{~mm})$. In this study, the method of Hong et al. [17] based on the brightness temperature at $183.3 \pm 1 \mathrm{GHz}$ and the brightness temperature differences $\Delta T_{17}, \Delta T_{13}$, and $\Delta T_{37}$ is adapted to detect intense tropical thunderstorms from the SSMIS data at $150 \mathrm{GHz}$ and higher frequencies. The higher horizontal resolution of the channels between 150 and $190 \mathrm{GHz}$ of the SSMIS provides an opportunity to detect small cloud systems that may be missed using previous sensors. Moreover, the higher frequencies used here make the method more sensitive to smaller particles than can be detected by the brightness temperature depression at 37 and $85 \mathrm{GHz}$, respectively. The criteria to detect intense tropical thunderstorms are

$$
\Delta T_{17}>\Delta T_{13}>0 \mathrm{~K} \quad \Delta T_{17}>\Delta T_{37}>0 \mathrm{~K}
$$

and

$$
T_{\mathrm{f}} \leq T_{\mathrm{c}, \mathrm{f}}
$$

where $T_{\mathrm{f}}$ is the brightness temperature at the frequency $f$, which can be one of the four channels at $150,183.3 \pm 7$, $183.3 \pm 3$, and $183.3 \pm 1 \mathrm{GHz}$, respectively. $T_{\mathrm{c}, \mathrm{f}}$ is the brightness temperature threshold for frequency $f$ that is determined by the method of Zipser et al. [18].

Criterion (1) recognizes deep convective clouds according to the method of Hong et al. [17]. The basic idea can be explained intuitively as follows. If we denote the brightness temperature of the channel at $183 \pm X \mathrm{GHz}$ as $T_{X}(X=1,3$, or 7), then under cloud-free conditions we expect

$$
T_{7}>T_{3}>T_{1}
$$

because the nearer the frequency is to the center of the water vapor absorption line at $183 \mathrm{GHz}$, the higher the atmospheric opacity, and from the higher (thus colder) layers of the atmosphere stems the received radiation. In the presence of deep convective clouds, however, the radiation from the deeper 

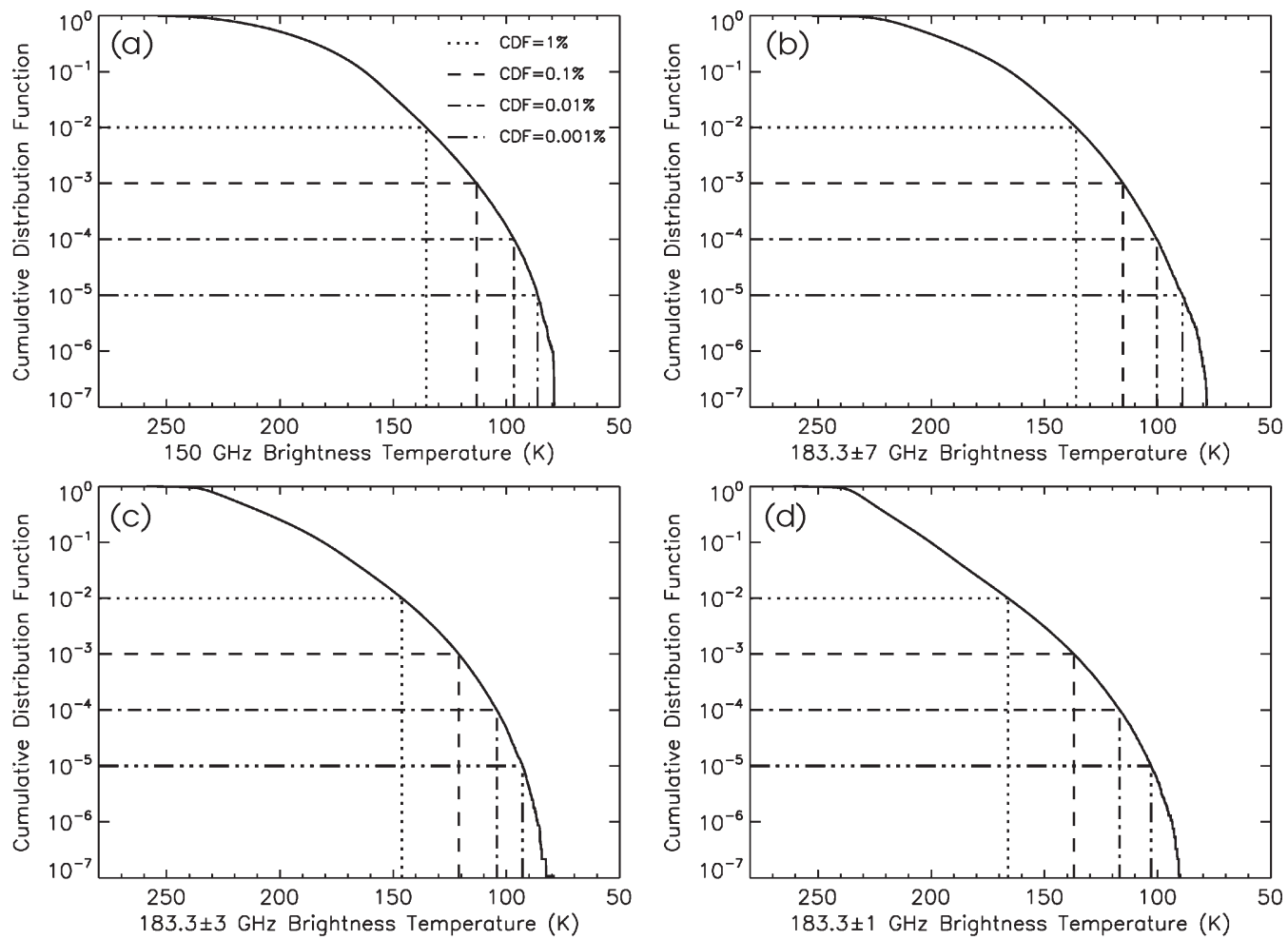

Fig. 1. Cumulative distribution functions $\left(C D F_{B T}\right)$ of brightness temperatures for tropical deep convective clouds detected from $(1)$ over $30^{\circ} \mathrm{S}-30^{\circ} \mathrm{N}$ during the period from December 2005 to November 2006. The upper thresholds for (2) are shown for the channels at (a) 150, (b) 183.3 \pm 7 , (c) 183.3 \pm 3 , and (d) $183.3 \pm 1 \mathrm{GHz}$

TABLE II

Threshold BRIGHTNESS TEMPERATURES $T_{\mathrm{c}, \mathrm{f}}$ AT SPECIFIED Frequencies AND CUMUlative Distribution FunCtions $\left(C D F_{B T}\right)$

\begin{tabular}{ccccc}
\hline $\begin{array}{c}\text { Frequencies } \\
\text { (GHz) }\end{array}$ & $C D F_{B T}<1 \%$ & $C D F_{B T}<0.1 \%$ & $C D F_{B T}<0.01 \%$ & $C D F_{B T}<0.001 \%$ \\
\hline 150.0 & 135.4 & 113.2 & 96.7 & 86.3 \\
$183.3 \pm 7$ & 136.0 & 115.3 & 100.4 & 89.1 \\
$183.3 \pm 3$ & 146.1 & 121.1 & 104.3 & 92.9 \\
$183.3 \pm 1$ & 166.1 & 137.0 & 116.8 & 102.9 \\
\hline
\end{tabular}

layers experiences more scattering than the radiation from the higher layers, and (3) reverses to

$$
T_{7}<T_{3}<T_{1}
$$

which directly leads to (1).

The cumulative brightness temperature distribution functions $\left(C D F_{B T}\right)$ for tropical deep convective clouds detected using (1) with different $T_{c, f}$ values for each frequency are shown in Fig. 1. Following the method of Zipser et al. [18], the $C D F_{B T}$ values less than $1 \%, 0.1 \%, 0.01 \%$, and $0.001 \%$, respectively, are used to categorize intense thunderstorms from detected storms by the SSMIS. The values of $T_{\mathrm{c}, \mathrm{f}}$ at each frequency for four types of thunderstorms with $C D F_{B T}<1 \%, 0.1 \%$, $0.01 \%$, respectively, and $0.001 \%$ are listed in Table II. They generally increase with the $C D F_{B T}$ threshold value (columns) and atmospheric opacity of the channels (rows). Thus, (2) provides a statistical classification of the deep convective clouds recognized by (1). It selects percentages of clouds of lowest brightness temperatures. Low brightness temperatures can be caused by cold targets (atmosphere and surface) or by particles in the radiation path to the sensor. Criterion (1) enforces the latter. That means the thresholds of (2) select pixels at those places where the convective clouds at the levels near the peak of the weighting function and above reduce the brightness temperature to the lower values of this channel according to the four $C D F_{B T}$ threshold values $1 \%, 0.1 \%, 0.01 \%$, and $0.001 \%$, respectively.

\section{RESULTS}

Fig. 2 shows the geographical distributions of intense tropical thunderstorms over $30^{\circ} \mathrm{S}-30^{\circ} \mathrm{N}$ during the period from December 2005 to November 2006. Criterion (2), with different brightness temperature thresholds shown in Table II for the four frequencies, is combined with (1) to identify the four types of intense thunderstorms corresponding to the four $C D F_{B T}$ intervals $1 \%>C D F_{B T}>0.1 \%, 0.1 \%>C D F_{B T}>0.01 \%$, $0.01 \%>C D F_{B T}>0.001 \%$, and $C D F_{B T}<0.001 \%$, respectively.

The intense tropical thunderstorms detected with $T_{\mathrm{c}, \mathrm{f}}$ at $150,183.3 \pm 7,183.3 \pm 3$, and $183.3 \pm 1 \mathrm{GHz}$, respectively, show similar patterns [Fig. 2(a)-(d)] with the exception of some intense thunderstorms around the coasts of South America [Fig. 2(b)] which are detected at $183.3 \pm 7 \mathrm{GHz}$. The major concentrations of the intense tropical thunderstorms are found over the Intertropical Convergence Zone (ITCZ), the South Pacific Convergence Zone (SPCZ), tropical Africa, the Indian Ocean, the Indonesia Maritime Continent, southern Asia, northern Australia, and tropical and South America. A weak double ITCZ shown by intense thunderstorms is found 

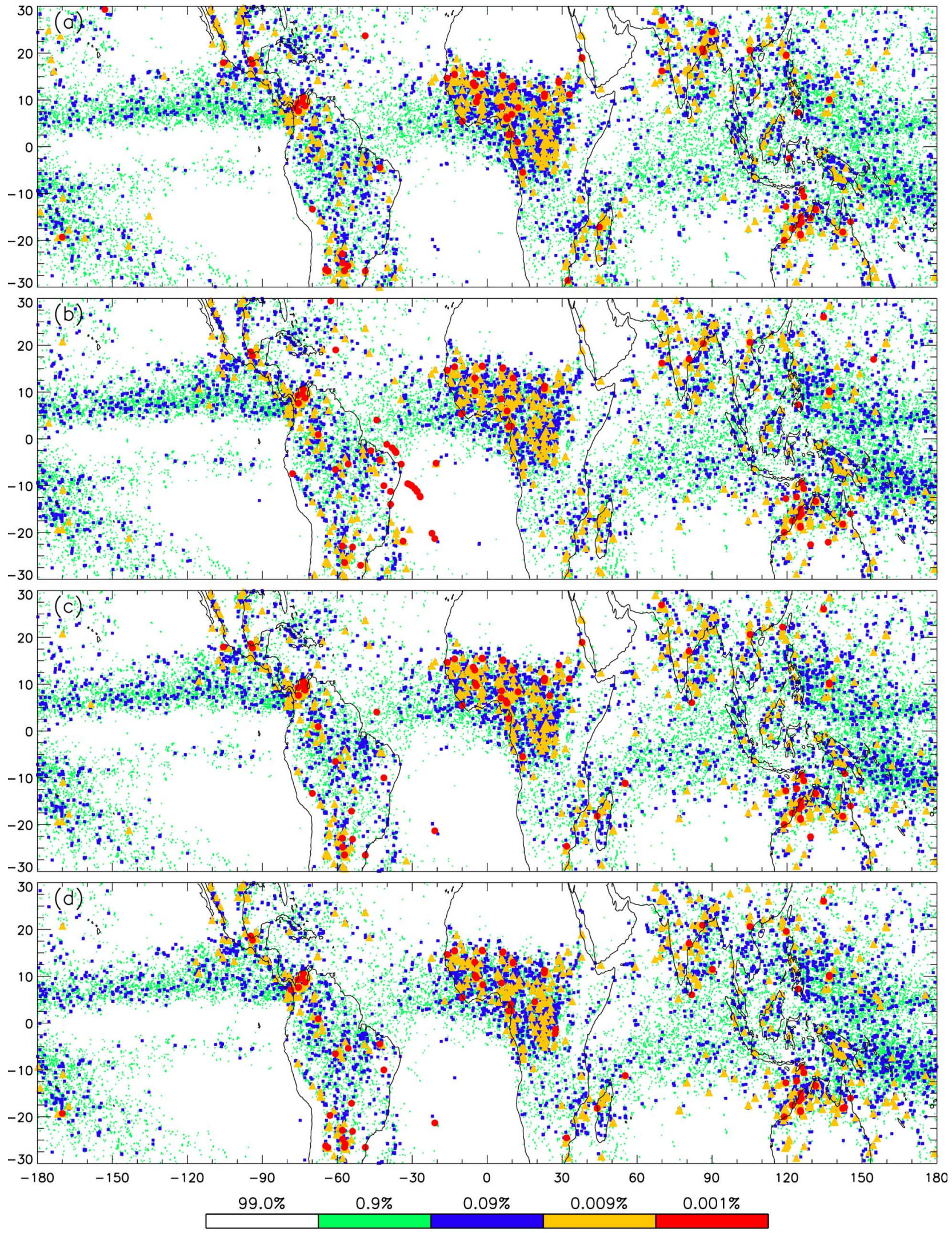

Probability Density Function

Fig. 2. Geographical distributions of the intense tropical thunderstorms over $30^{\circ} \mathrm{S}-30^{\circ} \mathrm{N}$ during the period from December 2005 to November 2006 . Four frequencies at (a) 150 , (b) $183.3 \pm 7$, (c) $183.3 \pm 3$, and (d) $183.3 \pm 1 \mathrm{GHz}$ are used. The four intensity types of thunderstorms with $C D F_{B T}$ intervals $1.0 \%>C D F_{B T}>0.1 \%, 0.1 \%>C D F_{B T}>0.01 \%, 0.01 \%>C D F_{B T}>0.001 \%$, and $C D F_{B T}<0.001 \%$, respectively, are marked with the same upper thresholds in Fig. 1. Corresponding brightness temperatures are listed in Table II. 


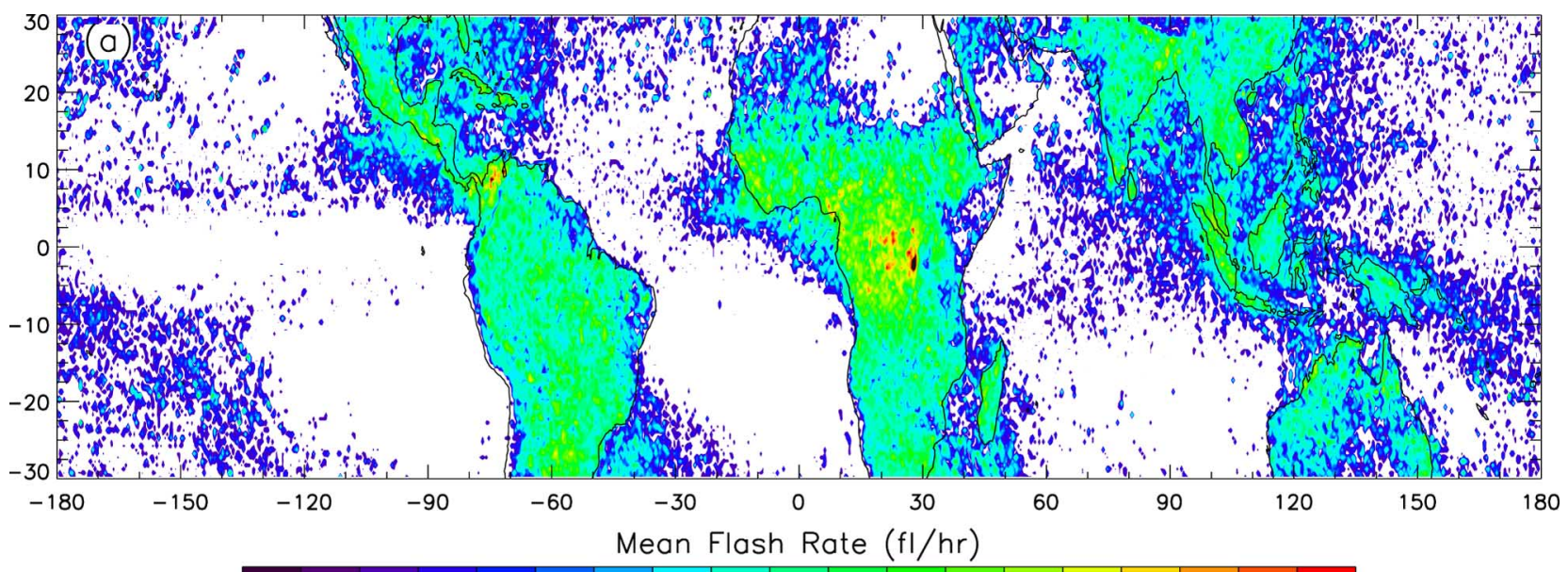

$\begin{array}{llllllllllllllllllll}0.1 & 0.2 & 0.4 & 0.6 & 0.8 & 1 & 2 & 4 & 6 & 8 & 10 & 15 & 20 & 25 & 30 & 35 & 40 & 45 & 50 & 55\end{array}$

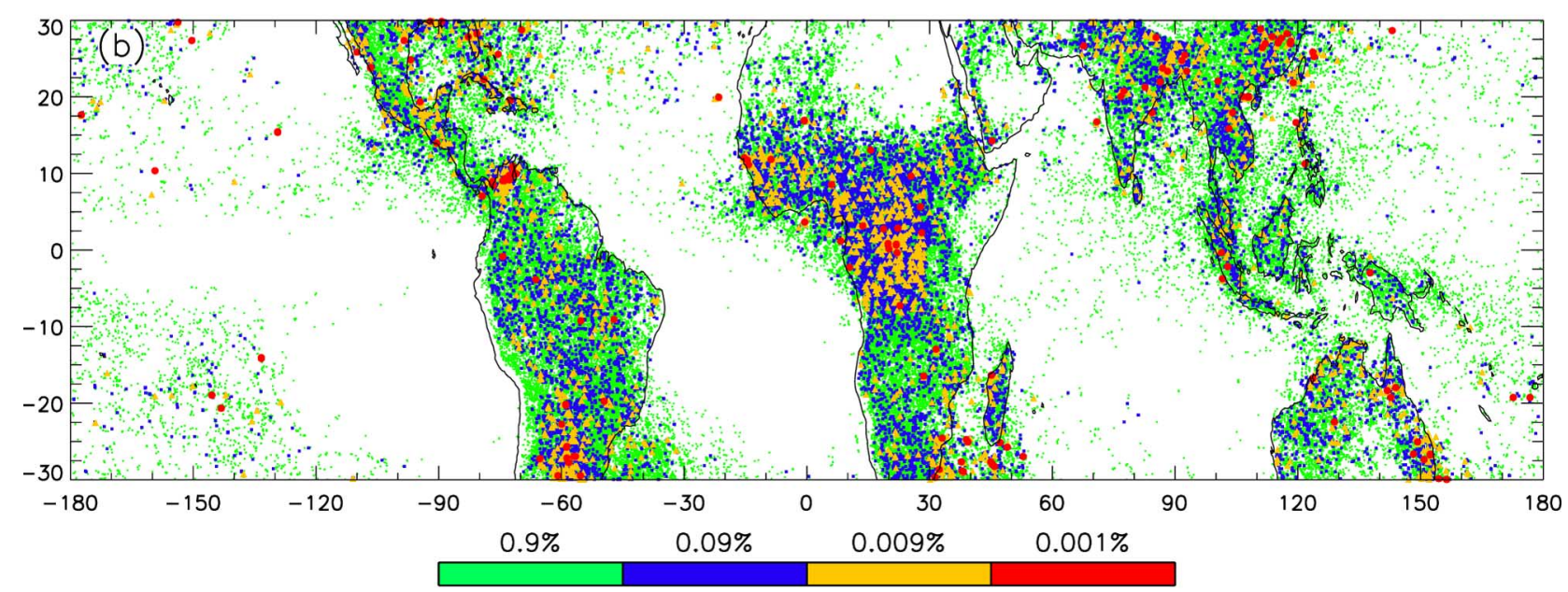

Probability Density Function

Fig. 3. (a) Geographical distributions of mean flash rates (fl/h) from TRMM LIS measurements in $0.5^{\circ} \times 0.5^{\circ}$ (longitude, latitude) over $30^{\circ} \mathrm{S}-30^{\circ} \mathrm{N}$ from December 2005 to November 2006. (b) Locations of the intense thunderstorms with flash rate $C D F_{L I S}$ intervals $1.0 \%>C D F_{L I S}>0.1 \%, 0.1 \%>$ $C D F_{L I S}>0.01 \%, 0.01 \%>C D F_{L I S}>0.001 \%$, and $C D F_{L I S}<0.001 \%$, respectively.

around $5^{\circ} \mathrm{S}$ over the eastern Pacific. The features of the intense thunderstorms are consistent with those of tropical deep convective clouds and convective overshooting [3], [4], [17]-[19], [37], [38].

The intense thunderstorms with $0.001 \%<C D F_{B T}<0.01 \%$ (yellow in Fig. 2, probability density function $=0.009 \%$ ) are concentrated over the region of $10^{\circ} \mathrm{S}-15^{\circ} \mathrm{N}$ in west Africa, the region over and around Madagascar, South America, the coastal regions of Central America and Mexico, southern Asia, the Bay of Bengal, the Maritime Continent, and northern Australia. Over the Indian Ocean, the SPCZ, and some regions around the ITCZ, there are a few scattered distributions of intense thunderstorms. The most intense thunderstorms with $C D F_{B T}<$ $0.001 \%$ (red) are predominant over land, with few exceptions over the South Atlantic for those detected by (2) at $183.3 \pm$ $7 \mathrm{GHz}$. Their preference over land has been found to be consistent with precipitation, convective clouds, and thunderstorms from independent measurements (e.g., [3], [4], [13], [17], [18], [36], [39], and [40]). Moreover, the intense thunderstorms detected by the SSMIS are mainly concentrated over Central and South America, tropical west Africa, and northern Australia.
The intense thunderstorms detected by the SSMIS are compared to those detected from the TRMM Lightning Imaging Sensor (LIS), which have been used to study tropical thunderstorms (e.g., [13], [18], and [36]). One year of TRMM LIS version 4 data from December 2005 to November 2006 were used to calculate the lightning flash rate and to identify the intense thunderstorm. Mean flash rates [flashes per hour, (fl/h)] were calculated by the ratio of the flash counts to the effective view times [41] in $0.5^{\circ} \times 0.5^{\circ}$ (longitude, latitude) boxes [Fig. 3(a)]. The lightning flash rate has been used to categorize precipitation features (e.g., [13], [18], and [36]). Cecil et al. [36] found that $2.4 \%$ of the detected precipitation features using their method had lightning from December 1997 to November 2000. The precipitation features with lightning that were associated with $1.0 \%>C D F_{L I S}>0.1 \%, 0.1 \%>C D F_{L I S}>0.01 \%$, $0.01 \%>C D F_{L I S}>0.001 \%$, and $C D F_{L I S}<0.001 \%$, respectively, of the total precipitation features have been identified as four categories of intense thunderstorms [18], [36]. These categories are used in this study. The lightning flash rates were calculated in $0.1^{\circ} \times 0.1^{\circ}$ boxes by dividing the flash counts by the effective view time, however, which were derived 
from the $0.5^{\circ} \times 0.5^{\circ}$ view times. The locations of the four categories of intense thunderstorms are shown in Fig. 3(b).

The geographical distributions and patterns of intense thunderstorms from the SSMIS (Fig. 2) are in agreement with those from the LIS (Fig. 3), which are also consistent with the results from Zipser et al. [18]. However, the intense thunderstorms with $C D F_{L I S}<0.001 \%$ from the LIS tend to cover more regions such as around southern Florida and Cuba, and south of China [Fig. 3(b)]. Also, the different temporal sampling schemes of the SSMIS and TRMM could result in some differences in distributions of thunderstorms detected by them. The sun-synchronous SSMIS crosses the equator at about 08:13 and 20:13 local time (http://www.wmo.ch/web/sat/ POLpresent.html), whereas the LIS can catch the diurnal variations of intense thunderstorms because TRMM samples the diurnal cycle for about 46 days when it returns to a given position at a given local time [42]. The strong influence of the diurnal cycle sampling strategy is also shown by the land-ocean contrast of the intense thunderstorms from the SSMIS and LIS. Strong convective clouds frequently occur in the afternoon over land, whereas in the morning the clouds occur over the ocean (e.g., [3], [21], and [42]). Thus, the intense thunderstorms from the LIS show much stronger land-ocean contrast than those from the SSMIS.

Seasonal variations of the two most intense thunderstorm types (with $C D F_{B T}$ values $<0.01 \%$ and $<0.001 \%$ shown in Fig. 2 in yellow and red) are illustrated in Fig. 4. The months December-February (DJF), March-May (MAM), June-August (JJA), and September-November (SON) are denoted as winter, spring, summer, and fall, respectively, in the Northern Hemisphere. Again, the extremely intense thunderstorms detected with $T_{\mathrm{c}, \mathrm{f}}$ at $150,183.3 \pm 7,183.3 \pm 3$, and $183.3 \pm 1 \mathrm{GHz}$, respectively [Fig. 4(a)-(d)] show very similar seasonal variations, which have also been found by independent measurements [4], [18], [36], [39], [40]. The intense thunderstorms already observed in Fig. 2(b) only at $183.3 \pm 7 \mathrm{GHz}$ off the coast of South America can now be attributed to the months JJA.

It is evident that the occurrence of extremely intense thunderstorms has a strong seasonal variation over most regions. Those over Central America are dominant in JJA and SON. Those over South America are dominant in DJF and MAM and also with some exceptions over the Amazon, Paraguay, and northern Argentina in JJA and SON [Fig. 4(a), (c) and (d)]. Additional exceptions include some intense thunderstorms around the coasts of South America [Fig. 4(b)] in JJA, which are detected with $T_{\mathrm{c}, \mathrm{f}}$ at $183.3 \pm 7 \mathrm{GHz}$. Similar to America, Africa also shows a pronounced seasonal migration. Extremely intense thunderstorms over southern Africa with latitudes greater than $5^{\circ} \mathrm{S}$ occur only in DJF and MAM. Those over northern Africa with latitudes greater than $10^{\circ} \mathrm{N}$ usually occur only in JJA and SON. In western Africa between $5^{\circ} \mathrm{S}$ and $10^{\circ} \mathrm{N}$, extremely intense thunderstorms occur all in four seasons, although they tend to occur more frequently in JJA and SON toward the northern regions and in DJF and MAM toward the southern regions. Over Australia, the Indian Ocean, and the Pacific with latitudes greater than $10^{\circ} \mathrm{S}$, extremely intense thunderstorms occur only in DJF and MAM. Extremely intense thunderstorms over southern India, the Arabian Sea, and the Bay of Bengal are dominant in DJF and MAM. Those over the regions with latitudes greater than $10^{\circ} \mathrm{N}$ over Southeast Asia and the West Pacific occur primarily in JJA and SON. Extremely intense thunderstorms over northern India and Bangladesh predominantly occur in JJA and, with some exceptions, in MAM. Over the Maritime Continent, extremely intense thunderstorms occur in all four seasons but less in JJA.

To investigate the occurrence frequencies of intense tropical thunderstorms, the fractions of thunderstorms with $C D F_{B T}<1 \%, 0.1 \%$, and $0.01 \%$, respectively, are calculated as the ratio of the counts flagged as intense thunderstorms to the total SSMIS observations within $2^{\circ} \times 2^{\circ}$ (latitude, longitude) boxes over the tropics from December 2005 to November 2006. Both the geographical distributions (Fig. 2) and the seasonal variations (Fig. 3) of intense tropical thunderstorms show similar patterns if any of the four frequencies $150,183.3 \pm 7,183.3 \pm 3$, and $183.3 \pm 1 \mathrm{GHz}$, respectively, are used. Because the $183.3 \pm 1-\mathrm{GHz}$ observations were used to derive information for precipitation and clouds [25], [33]-[35], we also use the $183.3 \pm 1-\mathrm{GHz}$ data here to study the fractions of intense thunderstorms. The total number of samples and fractions of intense thunderstorms with $C D F_{B T}<1 \%,<$ $0.1 \%$, and $<0.01 \%$ are shown in Fig. 5(b)-(d), respectively.

As Fig. 5(a) shows, the number of samples in the Southern Hemisphere is generally slightly larger than those in the Northern Hemisphere. Over South America, the Caribbean Sea, and partial regions of Southeast Asia and the Maritime Continent, the number of samples is much lower than other regions. Among them, those over the Amazon have the lowest values. The average number of samples in each grid box was 173-275 with a standard deviation of 5539 during the study period.

Intense thunderstorms with $C D F_{B T}<1 \%$ [Fig. 5(b)] frequently occur over the regions between $0^{\circ}$ and $10^{\circ} \mathrm{N}$ of Central America, the regions between $5^{\circ} \mathrm{S}$ and $15^{\circ} \mathrm{N}$ of west Africa, partial regions of the ITCZ and SPCZ, the western Bay of Bengal and its nearby coasts, and northern Australia. The distributions of fractions of intense thunderstorms with $C D F_{B T}<0.1 \%$ [Fig. 5(c)] are, in general, consistent with those of intense thunderstorms with $C D F_{B T}<1 \%$. The intense thunderstorms with $C D F_{B T}<0.1 \%$ are more frequent over land, however. The high fractions clearly shown over the ITCZ and SPCZ in Fig. 5(b) are much weaker for intense thunderstorms with $C D F_{B T}<0.1 \%$ shown in Fig. 5(c). This feature is more pronounced for the extremely intense thunderstorms with $C D F_{B T}<0.01 \%$ [Fig. 5(d)]. The fractions of extremely intense thunderstorms with $C D F_{B T}<0.01 \%$ are associated with the distribution densities shown in Fig. 2(b); the more concentrated the distributions, the higher the fractions of the intense thunderstorms. The higher fractions of the most intense thunderstorms with $C D F_{B T}<0.01 \%$ are mainly over Colombia, South America, tropical west Africa, and northern Australia. In conclusion, we find that the patterns of Fig. 4(b)-(d) are similar to those of the different colors of Fig. 2. However, Fig. 4(b)-(d) allows an estimate of the absolute frequency of the extremely intense thunderstorms in each of the $2^{\circ} \times 2^{\circ}$ grid cells. 

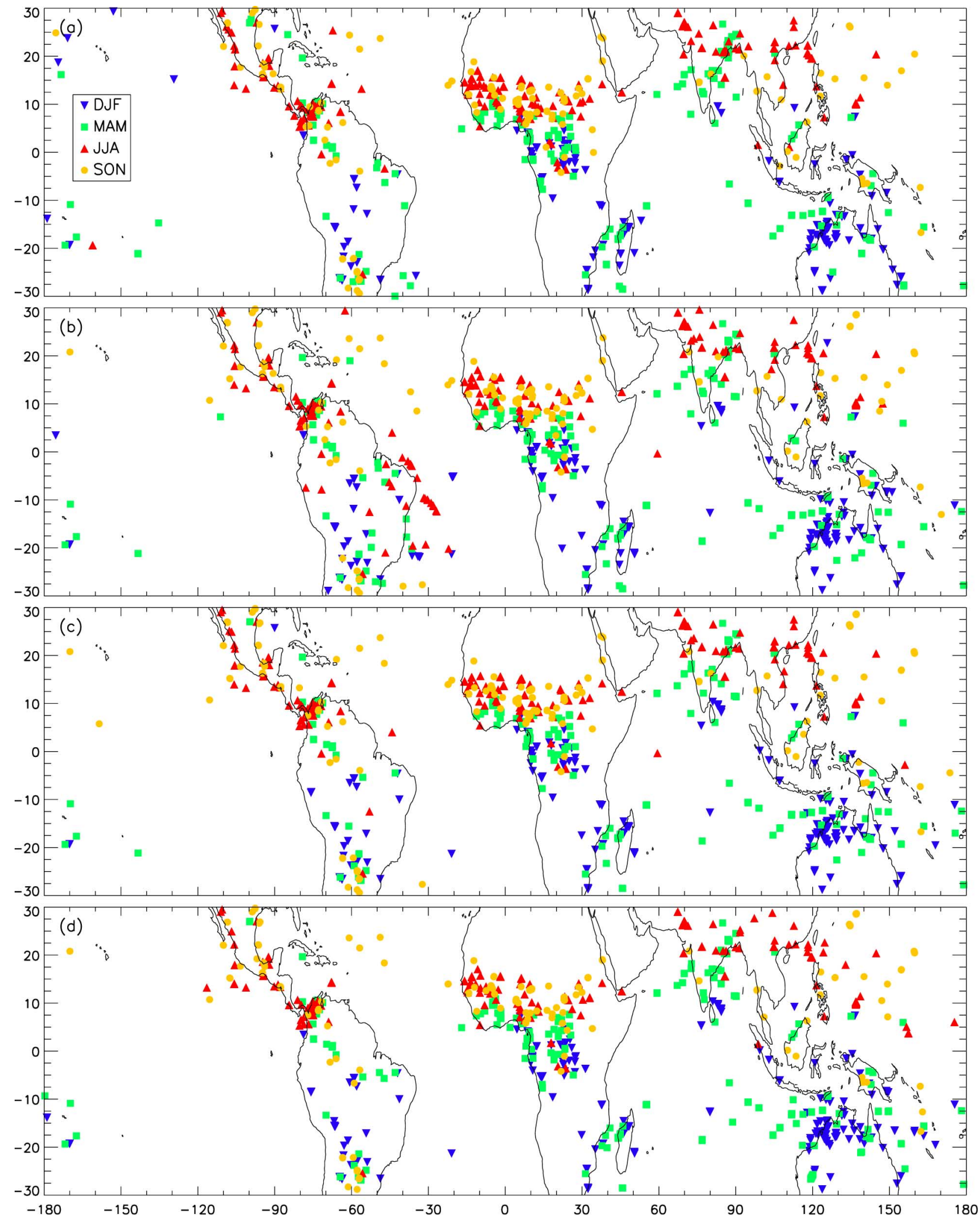

Fig. 4. Seasonal distributions of the intense thunderstorms with $C D F_{B T}<0.01 \%$ detected by the four channels at frequencies (a) 150 , (b) $183.3 \pm 7$, (c) $183.3 \pm 3$, and (d) $183.3 \pm 1 \mathrm{GHz}$.

\section{CONCLUSiON}

The SSMIS aboard DMSP F16 is the first conically scanning sensor covering high microwave frequencies at $150-190 \mathrm{GHz}$, in contrast to the previous sensors with similar frequencies, such as the SSM/T2, AMSU-B, and HSB, which employ a cross-track scanning scheme. The conical scanning allows having constant retrieval procedures, avoiding adjustments to the viewing angles, and thereby avoiding potential adjustment 

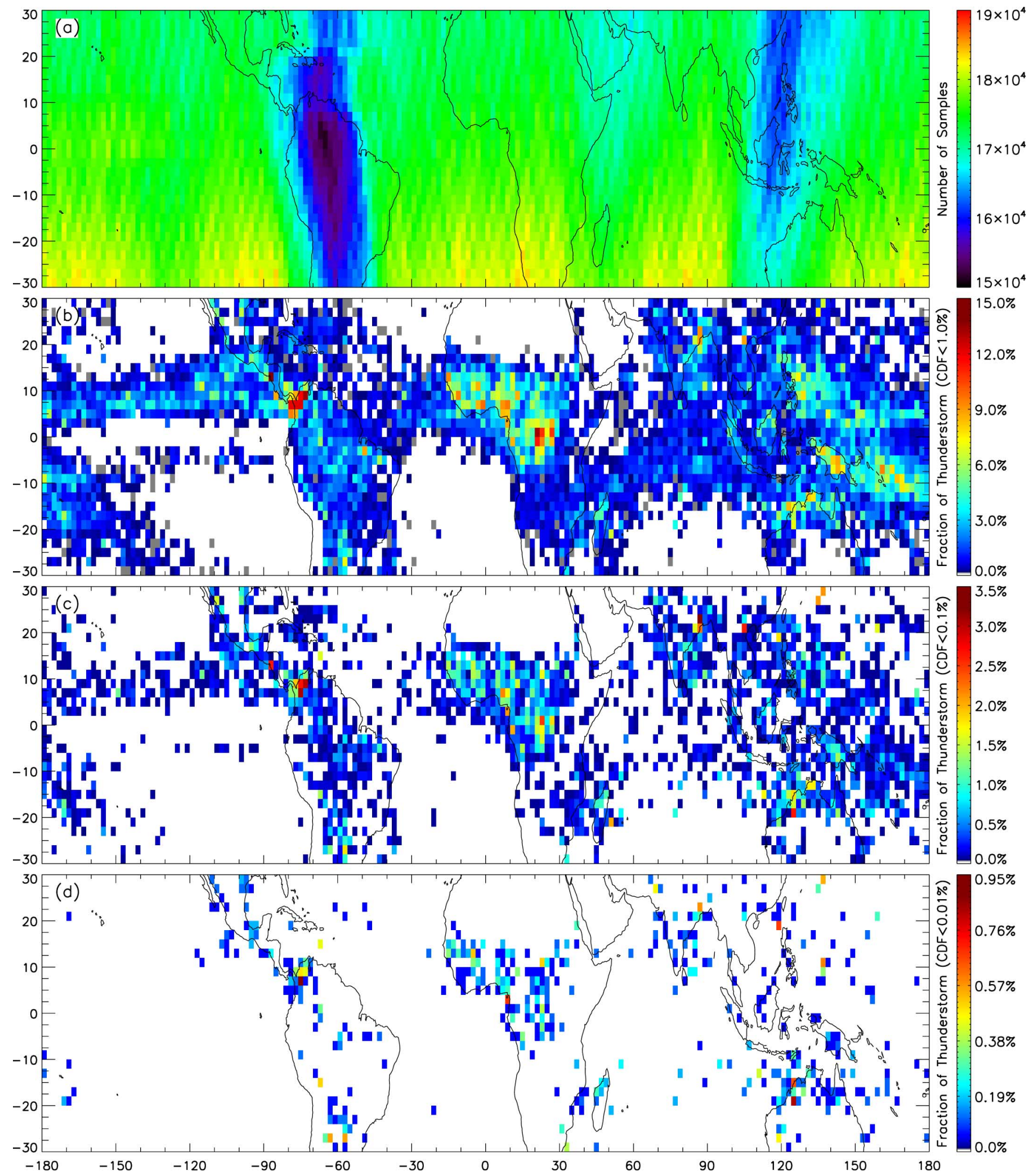

Fig. 5. (a) Number of samples of SSMIS measurements and fractions of intense tropical thunderstorms with (b) $C D F_{B T}<1.0 \%$, (c) $C D F_{B T}<0.1 \%$, and (d) $C D F_{B T}<0.01 \%$.

errors. Another advantage of SSMIS is the improvement of the horizontal resolution with respect to the SSM/T2, AMSU-B, and HSB.

The method for detecting tropical deep convective clouds [17] on the basis of the brightness temperature differences between the channels at $183.3 \pm 1$ and $183.3 \pm 7,183.3 \pm 1$ and $183.3 \pm 3$, and $183.3 \pm 3$ and $183.3 \pm 7 \mathrm{GHz}$, respectively, is combined with the brightness temperatures at 150 , $183.3 \pm 7,183.3 \pm 3$, and $183.3 \pm 1 \mathrm{GHz}$, respectively, to develop criteria to detect intense tropical thunderstorms. The 
tropical deep convective clouds with cumulative distribution function $\left(C D F_{B T}\right)$ values $<1 \%,<0.1 \%,<0.01 \%$, and $<0.001 \%$, respectively, were identified as four types of tropical thunderstorms of increasing intensity. Brightness temperature thresholds $T_{\mathrm{c}, \mathrm{f}}$ corresponding to these $C D F_{B T}$ thresholds were determined from the dataset.

The intense tropical thunderstorms over $30^{\circ} \mathrm{S}-30^{\circ} \mathrm{N}$ were surveyed using one year of SSMIS data from December 2005 to November 2006. The intense tropical thunderstorms detected with thresholds $T_{\mathrm{c}, \mathrm{f}}$ at $150,183.3 \pm 7,183.3 \pm 3$, and $183.3 \pm$ $1 \mathrm{GHz}$, respectively, show similar patterns [Fig. 2(a)-(d)]. The major concentrations of the intense tropical thunderstorms with $C D F_{B T}$ of $1 \%$ and $0.1 \%$ were found over the Intertropical Convergence Zone (ITCZ), the South Pacific Convergence Zone (SPCZ), tropical Africa, the Indian Ocean, the Indonesia Maritime Continent, southern Asia, northern Australia, and tropical and South America. The extremely intense tropical thunderstorms with $C D F_{B T}<0.01 \%$ and $<0.001 \%$ are predominant over land. These most intense tropical thunderstorms are mainly concentrated over Central and South America, tropical west Africa, and northern Australia (Fig. 2). The geographical distributions and patterns of intense thunderstorms from the SSMIS are in agreement with those from the LIS. Regional differences between the intense thunderstorms from the SSMIS and LIS are attributed to the sampling schemes of DMSP F16 (sun synchronous) and TRMM (not sun synchronous). However, sampling of the diurnal cycle with SSMIS will be extended by DMSP F17 launched on November 4, 2006 and the planned DMSP satellites also equipped with SSMIS instruments (http://www.wmo.ch/web/sat/POLfuture.html).

The seasonal variations of the intense tropical thunderstorms with a $C D F_{B T}$ of $0.01 \%$ were investigated (Fig. 4). The occurrence of intense tropical thunderstorms has a strong regional dependence over most regions. Furthermore, these extremely intense tropical thunderstorms have a pronounced seasonal migration. The fractions of intense tropical thunderstorms with a $C D F_{B T}$ of $1 \%$ and $0.1 \%$, respectively, have similar patterns [Fig. 5(b) and (c)]. They are frequent over the regions between $0^{\circ}$ and $10^{\circ} \mathrm{N}$ of Central America, the regions between $5^{\circ} \mathrm{S}$ and $15^{\circ} \mathrm{N}$ of west Africa, partial regions of the ITCZ and SPCZ, the western Bay of Bengal and its nearby coasts, and northern Australia. The tendency for extremely intense tropical thunderstorms to be over land is found for those with a $C D F_{B T}$ of $0.1 \%$, particularly for those with a $C D F_{B T}$ of $0.01 \%$ [Fig. 5(d)]. Those with a $C D F_{B T}$ of $0.01 \%$ are mainly over Colombia, South America, tropical west Africa, and northern Australia.

The convective clouds observed from satellites have been used to evaluate general circulation models (e.g., [3], [43], and [44]). Only a few of them have used clouds detected from microwave measurements, however [45]. Because the cloud properties detected from space were sensitive to the retrieval algorithms and sensors used [46], [47], it is important to evaluate the representation of clouds in general models using measurements from different sensors and retrieval methods [21]. The detected intense thunderstorms with different intensities from the SSMIS are complementary to those detected from other sensors, such as infrared sensor or cloud radar, and may evaluate the representations of their geographical and seasonal distributions in general circulation models.

\section{ACKNOWLEDGMENT}

The authors greatly appreciate Drs. C. D. Kummerow and M. Ringerud for providing the SSMIS Level 1C data, which was produced by the Precipitation Research Group led by Dr. Kummerow at Colorado State University. The TRMM LIS data are from http://ghrc.nsstc.nasa.gov/, provided by Dr. S. Harrison at the University of Alabama in Huntsville. They would like to thank Drs. D. Boccippio and J. Hall at the Marshall Space Flight Center, Mr. D. F. Buechler at the University of Alabama in Huntsville, and Dr. C. Liu at the University of Utah for LIS data processing assistance. The constructive comments of the anonymous reviewers and editors are gratefully acknowledged.

\section{REFERENCES}

[1] A. Gettelman, M. L. Salby, and F. Sassi, "The distribution and influence of convection in the tropical tropopause region," J. Geophys. Res., vol. 107, no. D10, 4080, 2002. DOI:10.1029/2001JD001048.

[2] J. Notholt et al., "Enhanced upper tropical tropospheric COS: Impact on the stratospheric aerosol layer," Science, vol. 300, pp. 307-310, 2004.

[3] B. Tian, B. J. Soden, and X. Wu, "Diurnal cycle of convection, clouds, and water vapor in the tropical upper troposphere: Satellites versus a general circulation model," J. Geophys. Res., vol. 109, no. D10, D10101, 2004. DOI:10.1029/2003JD004117.

[4] C. Liu and E. J. Zipser, "Global distribution of convection penetrating the tropical tropopause," J. Geophys. Res., vol. 110, no. D23, D23104, 2005. DOI:10.1029/2005JD006063.

[5] H. H. Hendon and K. Woodberry, "The diurnal cycle of tropical convection,” J. Geophys. Res., vol. 98, no. D9, pp. 16623-16638, 1993.

[6] T. J. Hall and T. H. Vonder Haar, "The diurnal cycle of west Pacific deep convection and its relation to the spatial and temporal variations of tropical MCSs," J. Atmos. Sci., vol. 56, no. 19, pp. 3401-3415, Oct. 1999.

[7] B. Lin, B. A. Wielicki, P. Minnis, L. Chambers, K.-M. Xu, Y.-X. Hu, and A. Fan, "The effect of environmental conditions on tropical deep convective systems observed from the TRMM satellite," J. Clim., vol. 19, no. 22, pp. 5745-5761, 2006.

[8] K.-Y. Wang and S.-A. Liao, "Lightning, radar reflectivity, infrared brightness temperature, and surface rainfall during the 2-4 July 2004 severe convective system over Taiwan area," J. Geophys. Res., vol. 111, D05206, 2006. DOI:10.1029/2005JD006411.

[9] R. W. Spencer, W. S. Olson, R. Wu, D. W. Martin, J. A. Weinman, and D. A. Santek, "Heavy thunderstorms observed over land by the Nimbus 7 scanning multichannel microwave radiometer," J. Clim. Appl. Meteorol., vol. 22 , no. 6, pp. 1041-1046, Jun. 1983

[10] R. W. Spencer, H. M. Goodman, and R. E. Hood, "Precipitation retrieval over land and ocean with SSM/I: Identification and characteristics of the scattering signal," J. Atmos. Ocean. Technol., vol. 6, no. 2, pp. 254-273, Apr. 1989.

[11] G. Liu, "Approximation of single scattering properties of ice and snow particles for high microwave frequencies," J. Atmos. Sci., vol. 61, no. 20, pp. 2441-2456, Oct. 2004.

[12] J. R. Wang, J. Zhan, and P. Racette, "Storm-associated microwave radiometric signatures in the frequency range of 90-220 GHz," J. Atmos. Ocean. Technol., vol. 14, no. 1, pp. 13-31, Feb. 1997.

[13] S. W. Nesbitt, E. J. Zipser, and D. J. Cecil, "A census of precipitation features in the tropics using TRMM: Radar, ice scattering, and lightning observations," J. Clim., vol. 13, no. 23, pp. 4087-4106, Dec. 2000.

[14] A. A. Kokhanovsky and W. von Hoyningen-Huene, "The optical properties of a hurricane," Atmos. Res., vol. 69, no. 3/4, pp. 165-183, Jan.-Mar. 2004.

[15] O. Kelley and J. Stout, "Convective towers in eyewalls of tropical cyclones observed by the TRMM precipitation radar in 1998-2001," presented at the 20th Conf. Weather Analysis Forecasting, Seattle, WA, 2004.

[16] R. R. Ferraro, F. Weng, N. C. Grody, L. Zhao, H. Meng, C. Kongoli, P. Pellegrino, S. Qiu, and C. Dean, "NOAA operational hydrological products derived from the Advanced Microwave Sounding Unit," IEEE Trans. Geosci. Remote Sens., vol. 43, no. 5, pp. 1036-1049, May 2005. 
[17] G. Hong, G. Heygster, J. Miao, and K. Kunzi, "Detection of tropical deep convective clouds from AMSU-B water vapor channels measurements," J. Geophys. Res., vol. 110, no. D9, D05205, 2005. DOI:10.1029/2004JD004949.

[18] E. J. Zipser, D. J. Cecil, C. Liu, S. W. Nesbitt, and D. P. Yorty, "Where are the most intense thunderstorms on Earth?" Bull. Amer. Meteorol. Soc., vol. 87, no. 8, pp. 1057-1071, Aug. 2006.

[19] Z. Luo and W. B. Rossow, "Characterizing tropical cirrus life cycle, evolution, and interaction with upper-tropospheric water vapor using Lagrangian trajectory analysis of satellite observations," J. Clim., vol. 17, no. 23, pp. 4541-4563, 2004.

[20] G. Hong, G. Heygster, J. Miao, and K. Kunzi, "Sensitivity of microwave brightness temperatures to hydrometeors in a tropical deep convective cloud system at 89-190 GHz," Radio Sci., vol. 40, no. 4, RS4003, 2005. DOI:10.1029/2004RS003129.

[21] G. Hong, G. Heygster, and C. A. M. Rodriguez, "Effect of cirrus clouds on the diurnal cycle of tropical deep convective clouds," J. Geophys. Res., vol. 111, no. D6, D06209, 2006. DOI:10.1029/2005JD006208.

[22] T. T. Wilheit, A. T. C. Chang, J. L. King, E. B. Rodgers, R. A. Nieman, B. M. Krupp, A. S. Milman, J. S. Stratigos, and H. Siddalingaiah, "Microwave radiometric observations near 19.35, 92 and $183 \mathrm{GHz}$ of precipitation in tropical storm Cora," J. Appl. Meteorol., vol. 21, no. 8, pp. 11371145, Aug. 1982.

[23] R. Bennartz and P. Bauer, "Sensitivity of microwave radiances at $85-183 \mathrm{GHz}$ to precipitating ice particles," Radio Sci., vol. 38, no. 4, 8075, 2003. DOI: $10.1029 / 2002 R S 002626$.

[24] F. Weng, L. Zhao, R. R. Ferraro, G. Poe, X. Li, and N. C. Grody, "Advanced Microwave Sounding Unit cloud and precipitation algorithms," Radio Sci., vol. 38, no. 4, 8068, 2003. DOI:10.1029/2002RS002679.

[25] F. W. Chen and D. H. Staelin, "AIRS/AMSU/HSB precipitation estimates," IEEE Trans. Geosci. Remote Sens., vol. 41, no. 2, pp. 410-417, Feb. 2003.

[26] C. Kongoli, P. Pellegrino, R. R. Ferraro, N. C. Grody, and H. Meng, "A new snowfall detection algorithm over land using measurements from the Advanced Microwave Sounding Unit (AMSU)," Geophys. Res. Lett., vol. 30, no. 14, 1756, 2003. DOI:10.1029/2003GL017177.

[27] G. M. Skofronick-Jackson, M.-J. Kim, J. A. Weinman, and D.-E. Chang, "A physical model to determine snowfall over land by microwave radiometry," IEEE Trans. Geosci. Remote Sens., vol. 42, no. 5, pp. 1047-1058, May 2004.

[28] M.-J. Kim, "Single scattering parameters of randomly oriented snow particles at microwave frequencies," J. Geophys. Res., vol. 111, no. D14, D14201, 2006. DOI:10.1029/2005JD006892.

[29] R. W. Saunders, T. J. Hewison, S. J. Stringer, and N. C. Atkinson, "The radiometric characterization of AMSU-B," IEEE Trans. Microw. Theory Tech., vol. 43, no. 4, pp. 760-771, Apr. 1995.

[30] W. Berg and C. Kummerow, "The climate rainfall data center: An online data service center," Bull. Amer. Meteorol. Soc., vol. 86, no. 9, pp. 12371240, Sep. 2005.

[31] G. Deblonde and S. English, "One-dimensional variation retrievals from SSMIS simulated observations," J. Appl. Meteorol., vol. 42, pp. 14061420,2003

[32] B. A. Burns, X. Wu, and G. R. Diak, "Effects of precipitation and cloud ice on brightness temperatures in AMSU moisture channels," IEEE Trans. Geosci. Remote Sens., vol. 35, no. 6, pp. 1429-1437, Nov. 1997.

[33] T. J. Greenwald and S. A. Christoper, "Effect of cold clouds on satellite measurements near $183 \mathrm{GHz}$," J. Geophys. Res., vol. 107, no. D13, 4170, 2002. DOI:10.1029/2000JD000258.

[34] S. A. Buehler and V. O. John, "A simple method to relate microwave radiances to upper tropospheric humidity," J. Geophys. Res., vol. 110, no. D2, D02110, 2005. DOI:10.1029/2004JD00511.

[35] S. A. Buehler, M. Kuvatov, T. R. Sreerekha, and V. O. John, "A cloud filtering method for microwave upper tropospheric humidity measurements," Atmos. Chem. Phys., vol. 7, no. 21, pp. 5531-5542, 2007.

[36] D. J. Cecil, S. J. Goodman, D. J. Boccippio, E. J. Zipser, and S. W. Nesbitt, "Three years of TRMM precipitation features. Part I: Radar, radiometric, and lightning characteristics," Mon. Weather Rev., vol. 133, no. 3, pp. 543-566, 2005 .

[37] C. M. Alcala and A. E. Dessler, "Observations of deep convection in the tropics using the Tropical Rainfall Measuring Mission (TRMM) Precipitation Radar," J. Geophys. Res., vol. 107, no. D24, 4792, 2002. DOI:10.1029/2002JD002457.

[38] J. H. Jiang, B. Wang, K. Goya, K. Hocke, S. D. Eckermann, J. Ma, D. L. Wu, and W. G. Read, "Geographical distribution and interseasonal variability of tropical deep convection: UARS MLS observations and analyses," J. Geophys. Res., vol. 109, no. D3, D03111, 2004. DOI:10.1029/2003JD003756.
[39] S. W. Nesbitt, E. J. Zipser, and C. D. Kummerow, "An examination of version-5 rainfall estimates from the TRMM Microwave Imager, Precipitation Radar, and rain gauges on global, regional, and storm scales," J. Appl. Meteorol., vol. 43, no. 7, pp. 1016-1036, Jul. 2004.

[40] C. Liu, E. J. Zipser, and S. W. Nesbitt, "Global distribution of tropical deep convection: Different perspectives from TRMM infrared and radar data," J. Clim., vol. 20, no. 3, pp. 489-503, Feb. 2007.

[41] H. J. Christian, R. J. Blakeslee, S. J. Goodman, and D. M. Mach, "Algorithm theoretical basis document (ATBD) for the Lightning Imaging Sensor (LIS)," Earth Observing System (EOS) Instrument Product, 2000.

[42] S. W. Nesbitt and E. J. Zipser, "The diurnal cycle of rainfall and convective intensity according to three years of TRMM measurements," J. Clim., vol. 16, no. 10, pp. 1456-1475, May 2003.

[43] W. Y. Lin and M. H. Zhang, "Evaluation of clouds and their radiative effects simulated by the NCAR community atmospheric model against satellite observations," J. Clim., vol. 17, no. 17, pp. 3302-3318, Sep. 2004.

[44] M. H. Zhang et al., "Comparing clouds and their seasonal variations in 10 atmospheric general circulation models with satellite measurements," J. Geophys. Res., vol. 110, no. D15, D15S02, 2005. DOI:10.1029/2004JD005021.

[45] J. C. Collier and K. P. Bowman, "Diurnal cycle of tropical precipitation in a general circulation model," J. Geophys. Res., vol. 109, no. D17, D17105, 2004. DOI: $10.1029 / 2004 J D 004818$.

[46] B. A. Wielicki and L. Parker, "On the determination of cloud cover from satellite sensors: The effect of sensor spatial resolution," J. Geophys. Res. vol. 97, no. D12, pp. 12 799-12 823, 1992.

[47] G. Hong, P. Yang, B.-C. Gao, B. A. Baum, Y. X. Hu, M. D. King, and S. Platnick, "High cloud properties from three years of MODIS Terra and Aqua data over the tropics," J. Clim. Appl. Meteorol., vol. 46, no. 11, pp. 1840-1856, Nov. 2007

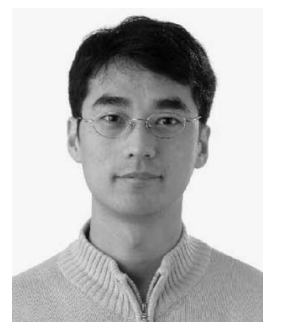

Gang Hong received the B.S. degree in atmospheric sciences from the Nanjing Institute of Meteorology, Nanjing, China in 1995, and the Ph.D. degree in environmental physics and remote sensing from the University of Bremen, Bremen, Germany in 2004.

$\mathrm{He}$ is currently an Assistant Research Scientist with the Department of Atmospheric Sciences, Texas A\&M University, College Station. His research interest is primarily in satellite remote sensing of clouds and its application to climate study. Recent research has centered on retrieving ice cloud and aerosol properties and investigating radiative properties of clouds from MODIS and AIRS measurements. He is also working on the development of scattering properties of nonspherical ice crystals at millimeter and submillimeter wavelengths.

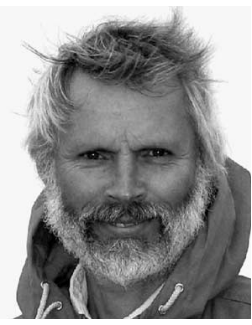

Georg Heygster (M'00) received the diploma degree in solid-state physics in 1976 and the Ph.D. degree in digital image processing in 1979 from the University of Göttingen, Göttingen, Germany.

He served as a Consultant at the Computer Center of the University of Bremen from 1979 to 1988. Since then, after working for one year on the imaging mechanisms of scanning acoustic microscopes, he has been Head of the Geophysical Analysis of Satellite Images group at the Institute of Environmental Physics, University of Bremen. His research activities include passive and active microwave remote sensing, particularly of both surface and atmospheric parameters in the high latitudes, various aspects of the hydrological cycle, long-term trends, and retrieval techniques. He was or still is Principal Investigator or Coinvestigator of many research projects funded by the European Union, the European Space Agency, DF, and the Japan Aerospace Exploration Agency, including the development of sensor software and hardware, conducting campaigns, the final data analysis from multi- and single-sensor data to geophysical parameters, and the interpretation and application of these results in such areas such as meteorology, climatology, and oceanography. 